\title{
A Late Holocene Sea Level Rise Event Inferred from Precisely Dated Speleothems from Mallorca
}

YEMANE ASMEROM ${ }^{1 *}$, BOGDAN P. ONAC ${ }^{2}$ JERRY X. MitroviCA ${ }^{3}$, PAOLA TUCCIMEI ${ }^{4}$, JOAN J. FORNÓs ${ }^{5}$, VICTOR J. POLYAK ${ }^{1}$, JOAQUÍN GINÉS ${ }^{5}$, ANGEL GINÉS ${ }^{5}$, MiCHELE SOLIGO ${ }^{4}$, IGOR VILLA ${ }^{6}$

${ }^{11}$ Dept. of Earth and Planetary Sciences, University of New Mexico, Albuquerque, NM, USA. *asmerom@unm.edu

${ }^{2}$ Karst Research Group, School of Geosciences, University of South Florida, Tampa, FL, USA.

${ }^{3}$ Dept. of Earth and Planetary Sciences, Harvard University, Cambridge, MA, USA.

${ }^{4}$ Dipartimento di Scienze, Università "Roma Tre", Largo San Leonardo Murialdo 1, 00146 Roma, Italy.

${ }^{5}$ Earth Sciences Research Group, Universitat de les Illes Balears, Palma, Spain.

${ }^{6}$ Institute of Geology, Bern University, Baltzerstrasse 1, 3012 Bern, Switzerland.

Pre-industrial Holocene eustatic sea level variability provides the background state against which changes due to greenhouse warming may be calibrated. Our understanding of post deglacial Holocene sea level is limited by the lack of precisely dated proxies with narrow indicative range. Phreatic overgrowths on speleothems, preferably aragonitic types, grow in littoral caves in a narrow range $( \pm 12.5 \mathrm{~cm})$ of ambient sea level. Given their high uranium concentration, they are accurately dateable with uranium-series chronology.

We have previously shown that these Mallorcan sites have remained tectonically stable [1]. We report an accurately and precisely dated $( \pm 1.3 \%$ average $2 \sigma$ errors) record of Late Holocene relative sea level (RSL) from these sites. Our record shows that RSL for the last $3900 \mathrm{ybp}(p=2010 \mathrm{CE})$ was stable near present sea level, with the exception of a rapid 0.25 meters rise in RSL between 3250 and $2800 \mathrm{ybp}$. The most plausible explanation for the event involves melting from the Antarctic and/or Greenland ice sheets. Although lacking precise chronologies, several indicators elsewhere hint at Antarctic melting episodes around that time [e.g. Ref. 2 and references therein]. A stable RSL near present sea level for the last 2800 years agrees with global sea level reconstructions [3], providing a reference point for current and future sea level rise. Additionally, the analysis will yield constraints on regional mantle rheology, necessary for geophysical modeling. [1] Polyak et al. (2018) Nat. Geosci. 11, 860-864. [2] Yokoyama et al. (2019) Quat. Sci. Rev. 206, 150-161. [3] Kopp et al. (2016) PNAS 113, E1434-E1441. 